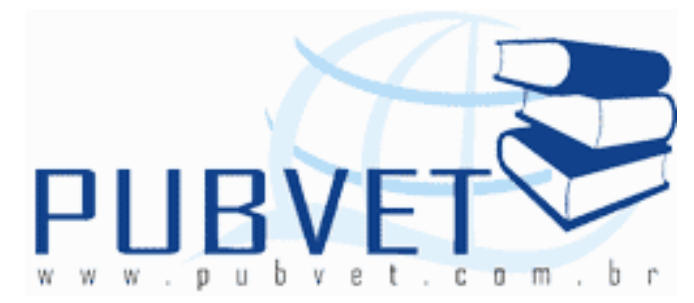

PUBVET, Publicações em Medicina Veterinária e Zootecnia.

\title{
A importância do diagnóstico e tratamento da fasciolose em rebanhos bovinos
}

Bethânia Ribeiro de Almeida ${ }^{1}$, Fabiano Costa Santiliano ${ }^{2}$, Danielle Porcari Alves $^{3}$, Olavo dos Santos Pereira Júnior ${ }^{1}$

${ }^{1}$ Docente. Centro de Ciências Agrárias da Universidade Federal do Espírito Santo.

${ }^{2}$ Biólogo. Centro de Ciências Agrárias da Universidade Federal do Espírito Santo.

3 Médica Veterinária. Centro de Controle de Zoonoses de Cachoeiro de Itapemirim.

\section{Resumo}

A fasciolose é uma doença parasitária causada por duas espécies de trematódeos, Fasciola hepatica e Fasciola gigantica. Considerada uma zoonose com ampla distribuição geográfica, é capaz de limitar a criação de diversas espécies de animais domésticos de interesse zootécnico, além de acometer o homem como hospedeiro ocasional, existindo aproximadamente 180 milhões de pessoas com risco de infecção e uma estimativa de que cerca de 2,4 milhões já estejam infectadas. A prevalência é alta em áreas que apresentam criações de ruminantes. Consistindo uma das doenças parasitárias de maior relevância em animais de interesse econômico no mundo, sua importância deve-se, principalmente, às perdas associadas com condenações de fígados, 
mortalidade, redução em produção de carne, lã e leite, às infecções bacterianas secundárias, à interferência com a fertilidade e aos custos com tratamentos antihelmínticos (fasciolicidas). Assim, objetivou-se com a presente revisão descrever a importância do diagnóstico e do tratamento da fasciolose hepática em rebanhos bovinos.

Palavras-chave: Fasciola hepatica, Fasciolose, bovinos.

\title{
The importance of diagnosis and treatment of fasciolosis in cattle
}

\begin{abstract}
The fascioliasis is a parasitic disease caused by two species of trematodes, Fasciola hepatica and Fasciola gigantica. Considered a zoonosis with wide geographical distribution, is able to limit the creation of several species of domestic animals of zootechnical interest, and affect men as occasional host, there were approximately 180 million people at risk of infection and estimated that about 2.4 million are already infected. The prevalence is high in areas that are creations of ruminants. Consisting of the most relevant parasitic disease in animals of economic interest in the world, its importance is due mainly to losses associated with condemnation of livers, mortality, reduction in production of meat, wool and milk, to secondary bacterial infections, the interference with fertility and the costs of anthelmintic treatments (fasciolicidas). Thus, the objective with the present review was to describe the importance of diagnosis and treatment of liver fasciolosis in cattle.
\end{abstract}

Keywords: Fasciola hepatica, Fascioliasis, cattle.

\section{Introdução}

As infecções parasitárias encontram-se, ainda hoje, disseminadas no mundo, apesar dos avanços no campo de medicamentos antiparasitários polivalentes. Isso se deve às condições sanitárias, aos comportamentos e hábitos dos seres humanos e ao nível de educação e cultura de certas populações. A fasciolose é uma doença parasitária causada por duas espécies 
de trematódeos, Fasciola hepatica e Fasciola gigantica. Considerada uma zoonose com ampla distribuição geográfica, é capaz de limitar a criação de diversas espécies de animais domésticos de interesse zootécnico, além de acometer o homem como hospedeiro ocasional (BARROS, 2002), existindo aproximadamente 180 milhões de pessoas com risco de infecção e uma estimativa de que cerca de 2,4 milhões já estejam infectadas. A prevalência é alta em áreas que apresentam criações de ruminantes. Consistindo uma das doenças parasitárias de maior relevância em animais de interesse econômico no mundo, sua importância deve-se, principalmente, às perdas associadas com condenações de fígados, mortalidade, redução em produção de carne, lã e leite, às infecções bacterianas secundárias, à interferência com a fertilidade e aos custos com tratamentos antihelmínticos (fasciolicidas) (ECHEVARRIA, 2004).

Historicamente, nos estados do Rio Grande do Sul, Santa Catarina, Paraná, São Paulo, Rio de Janeiro e Minas Gerais vêm sendo reportada a incidência de fasciolose bovina, notadamente em sua forma crônica, com dados de propriedades, matadouros e de exames coproparasitológicos (SERRAFREIRE et al., 1995). Estes dados revelam ainda uma alta freqüência no Rio Grande do Sul, especialmente no sul e sudeste do estado, onde a fasciolose é endêmica.

De acordo com SERRA-FREIRE (1995), a F. hepatica está presente em quatro das cinco regiões geográficas brasileiras, distribuindo-se seguramente em oito estados do Brasil. Segundo o mesmo autor, a região Sul apresentou o maior coeficiente de ocorrência da fasciolose. No Rio Grande do Sul o parasitismo aconteceu em $23,87 \%$ dos municípios, no estado de Santa Catarina em 43,69\% e no Paraná em 36,77\%. O município de Santa Vitória do Palmar (RS) apresentou 25 a 100\% de mortes de ovinos e também, os mais altos índices de condenação de fígados em frigoríficos, sendo $50 \%$ para bovinos e 7\% para ovinos (MÜLLER et al., 1998).

Em Santa Catarina, nas regiões que compreendem o Vale do Itajaí e o Litoral Catarinense, entre 1980 e 1981, foram realizados exames de fezes em 
770 bovinos com aptidão leiteira. No Vale do Itajaí e Litoral Norte, a prevalência foi de $46,7 \%$, na região que engloba o Litoral Centro foi de 39,4\% e no Litoral Sul a prevalência foi de $48,3 \%$. Em trabalho realizado no Vale do Rio dos Bugres, Planalto Catarinense, constataram uma prevalência de 49,1\% no rebanho bovino daquela localidade (BOTELHO, 2002). Na região Sudeste, o estado de São Paulo detém o maior número de ocorrências, com 22,45\% dos municípios (MÜLLER et al., 1998).

O tratamento para fasciolose deve ser realizado sob a forma de controle de vetores e tratamento farmacológico dos doentes, o que, deve ser realizado preferencialmente por antihelmínticos que apresentam fácil aplicação, evitando resíduos na carne e leite, e que sejam altamente eficazes contra formas adultas e imaturas de F. hepatica. Este perfil de produto nem sempre é encontrado e por isso a freqüência das medicações dependerá da eficiência do fasciolicida e do grau de exposição dos animais às áreas altamente contaminadas (BIANCHIN, 2000). Objetivou-se com a presente revisão descrever a importância do diagnóstico e do tratamento da fasciolose hepática em rebanhos bovinos.

\section{Fasciola hepatica}

A fascíola (Fasciola hepatica) é um verme achatado, trematódeo da família dos fasciolídeos, filo Platyhelminthes, parasito dos canais biliares de ruminantes e, raramente, do homem. Apresenta corpo de coloração avermelhada, foliáceo, achatado, com ventosa oral pequena e faringe bem desenvolvida. Também conhecida pelos nomes de barata-do-fígado, baratinhado-fígado, dúvia e saguaipé. Para completar seu ciclo de vida, o parasito necessita de um hospedeiro intermediário, moluscos do gênero Lymnaea; os quais possuem dois representantes no Brasil: Lymnaea columella e L. viatrix, sendo L. columella, por sua ampla distribuição, o hospedeiro intermediário de maior interesse epidemiológico no país. Os ovos de $F$. hepatica apresentam opérculos de aproximadamente $140 \mu \mathrm{m}$ de comprimento e $75 \mu \mathrm{m}$ de largura. 
O ciclo de vida da $F$. hepatica requer dois hospedeiros. O hospedeiro vertebrado se infecta ao ingerir pasto contaminado com metacercárias que se encistam no intestino delgado, migram para a parede intestinal, caem na cavidade abdominal e penetram no parênquima hepático, atingindo os canais biliares onde se fixam e se tornam adultos. Os parasitos adultos são grandes produtores de ovos. Cada adulto pode produzir entre 20.000 e 50.000 ovos/dia. Os ovos não embrionados são liberados pelas fascíolas adultas e eliminados junto com as fezes, e uma vez no meio externo, em área úmida e com temperaturas médias acima de $10^{\circ} \mathrm{C}$, irão eclodir liberando miracídios. A eclosão ocorre em 21 dias no verão e pode chegar a 90 dias durante o outono e primavera. Os miracídeos nadam ativamente atraídos por quimiotaxia dos caramujos, em especial $L$. viatrix e $L$. columella, seus hospedeiros invertebrados. No molusco, o miracídio dá origem às rédias e aos esporocistos, que se desenvolvem e dão origem às cercárias. De um miracídio podem ser produzidas 4.000 cercárias.

O ciclo no molusco tem duração de dois a três meses, conforme as condições climáticas. Os esporocistos e as rédias podem regular seu desenvolvimento conforme as condições externas. Estes ao serem liberados na água migram para objetos sólidos como folhas de capins onde se transformam em metacercárias, o estágio infectivo para o hospedeiro definitivo. $O$ bovino ao se alimentar, ingere a metacercária, a qual perfura a mucosa do intestino delgado, atinge a cavidade peritoneal e migra para o fígado até alcançar o ducto biliar onde atinge a maturidade, eliminando os ovos e fechando o ciclo. As metacercárias permanecem viáveis por muitas semanas, dependendo da temperatura. A sobrevivência é maior abaixo de $20^{\circ} \mathrm{C}$, temperaturas altas e a dessecação destruirão as mesmas em curto espaço de tempo.

Os moluscos produzem ovos que podem eclodir sempre que a temperatura estiver acima de $10^{\circ} \mathrm{C}$. A reprodução destes animais aumenta durante as estações chuvosas, mas diminui e, é até mesmo interrompida com a chegada do frio e em períodos de seca. O gênero Lymnaea pode produzir 3.000 ovos/ mês e uma geração de molusco, de ovo a ovo, pode levar apenas 
um mês quando as condições climáticas são favoráveis. Os moluscos podem sobreviver na lama seca por vários meses e também sobrevivem a baixas temperaturas.

A produção de ovos pelos parasitos adultos, juntamente com as condições climáticas favoráveis para a sobrevivência dos moluscos, irá determinar o grau de infecção das pastagens. Em bovinos, a produção de ovos pelo parasito declina com a idade, pois o animal desenvolve imunidade adquirida frente a infecções crônicas. A epidemiologia da fasciolose é influenciada pelo hábito de pastejo dos animais. Os bovinos, por exemplo, pastejam áreas de banhados, mananciais e pequenos córregos, habitat preferencial do hospedeiro intermediário, deste modo proporcionando a continuação do ciclo. Já os ovinos preferem pastejar áreas não alagadiças. Longos períodos úmidos são geralmente associados a altas infecções por $F$. hepatica, mas os ovinos irão se infectar, principalmente, após um período de seca depois de uma estação chuvosa, quando essa espécie, então, inicia a alimentação nessas áreas mais úmidas, o que os leva à exposição de altas cargas parasitárias (ECHEVARRIA, 2004).

\subsection{PATOLOGIA}

A infecção de bovinos depende de diversos fatores, como: condições climáticas, solo, vegetação, sistema de exploração, raça, idade do animal e o tipo de pastagem. As infeç̧ões quando maciças podem causar mortalidade de até $10 \%$ tal como ocorre na Região Sul do País. Nas criações extensivas de bovinos de corte na região Central do Brasil, a média é baixa, 2\%, e a verminose se manifesta, principalmente, na forma de baixos índices de crescimento dos animais. Em criações mais intensivas, os animais são forçados ao pastejo sem seletividade e próximo às fezes, aumentando os riscos de contaminação (BIANCHIN, 2000).

O desenvolvimento da infecção por $F$. hepatica ocorre de forma distinta em ovinos e bovinos. Raramente a fasciolose aguda chega a provocar mortes 
em bovinos, porém em ovinos a mortalidade pode atingir índices que variam entre 15 e $20 \%$. Os bovinos desenvolvem uma gradual resistência às infecções, enquanto que os ovinos são altamente sensíveis. Dentre as diferenças patológicas verificadas nas duas espécies, destaca-se o grau de calcificação das lesões tissulares e a hiperplasia dos ductos biliares. Ambas as reações apresentam-se mais evidentes em bovinos do que em ovinos. Em bovinos pode ocorrer uma recuperação espontânea devido à calcificação dos ductos biliares, que pode ocasionar inanição e morte do parasito.

A presença de fascíola pode ser detectada macroscopicamente no tecido hepático, uma semana após a entrada das formas infectantes através do lóbulo ventral do fígado. Nas semanas seguintes, aparecem pontos brancos no parênquima hepático e, paralelamente ao crescimento dos parasitos, dá-se o rompimento das células hepáticas. Na $6^{a}$ semana após o início da infecção acontece a ruptura dos vasos sanguíneos, com a conseqüente formação de coágulos. A partir desta fase, o lóbulo ventral torna-se visualmente menor, mais rígido, e a superfície hepática apresenta muitas marcas. A degeneração do lóbulo ventral é parcialmente compensada pelos nódulos regenerativos nos outros lóbulos. Este efeito é notado principalmente 20 semanas após a infecção.

A presença do parasito adulto no ducto biliar determina peri-fibrose ductal com engrossamento do canal (Colangiohepatite). Com a chegada da fascíola no ducto biliar, com aproximadamente 8 semanas, ocorre início de anemia e as perdas produtivas (leite e carne). Alguns casos esporádicos têm sido relatados na literatura apontando a fasciolose hepática como determinante de obstrução biliar, ocasionando icterícia obstrutiva (CORAL et al., 2007).

Na 30a semana pós-infecção, em alguns animais, principalmente ovinos, o lóbulo ventral fica reduzido a um apêndice fibroso e os lóbulos central e dorsal tornam-se dilatados, nodulados e com os ductos biliares proeminentes. A formação de colágeno em torno dos caminhos migratórios das formas imaturas ocorre em torno da $6^{a}$ semana pós-infecção, aumentando em 
tamanho e número, transformando-os em focos de cicatrizes tissulares. Estas cicatrizes tissulares aderem às estruturas vizinhas (sistema portal, cápsula e veias hepáticas) por feixes de colágeno. O colágeno também é derramado nas paredes das vias portais e hepáticas adjacentes, podendo provocar sua oclusão.

No período compreendido entre a $12^{\mathrm{a}}$ e a $20^{\mathrm{a}}$ semana após a infecção, as artérias sofrem hiperplasia. Apesar de bastante significativos, estes não são os únicos efeitos provocados pela presença de $F$. hepatica no hospedeiro definitivo. Há também a hiperplasia e a calcificação dos ductos biliares, comumente encontrados na forma crônica da fasciolose, e a anemia, o sintoma mais característico. Esta acontece tanto na forma aguda quanto na crônica, provocada pela remoção de sangue pela fasciola e pelas lesões que provocam extensas hemorragias (ANTUNES, 2005).

Contaminações secundárias agudas também podem ocorrer em ovinos e bovinos. Isto está, normalmente, associado com a lesão causada pela migração de formas jovens no tecido hepático; esta lesão proporciona um ambiente favorável à esporulação da bactéria Clostridium novyi, tipo $B$, no fígado (ECHEVARRIA, 2004). A fase aguda da doença ocorre quando as formas jovens estão migrando pelo parênquima hepático, destruindo as células e causando focos hemorrágicos difusos, no entanto, esta fase raramente se manifesta em bovinos, ocasionalmente em terneiros (bezerros), porém dificilmente causando morte. Os bovinos desenvolvem resistência à fascíola.

A fase crônica da fasciolose é a mais importante em bovinos. O fígado apresenta-se pálido, com lobo ventral atrofiado, calcificação das lesões tissulares, fibrose e acentuado engrossamento da parede dos ductos biliares (hiperplasia) de maneira que estes se tornam visíveis na superfície do órgão. Nas infecções maciças, com anemia e hipoalbuminemia, os terneiros podem apresentar edema submandibular. A migração de fascíolas para o pulmão, formando abscessos, é relativamente comum em bovinos (ANTUNES, 2005). 


\subsection{AVALIAÇÃO ECONÔMICA}

A avaliação econômica resulta em prejuízos classificados como diretos e indiretos, sendo estes associados à redução no ganho de peso por animal (tabela 1), condenação de fígado, redução na produção de leite, redução nas taxas de concepção, bem como o aumento no custo de produção (ANTUNES, 2005).

Tabela 1. Prejuízos econômicos em bovinos acometidos com fasciolose, correlacionando o grau de infecção com a perda de peso estimada por animal.

\begin{tabular}{cc}
\hline Grau de Infecção & $\begin{array}{c}\text { Perdas estimadas por } \\
\text { animal em Kg }\end{array}$ \\
\hline Leve & 1 a $2 \mathrm{Kg}$ \\
\hline Moderado & 3 a $8 \mathrm{Kg}$ \\
\hline Severa & 25 a $50 \mathrm{Kg}$ \\
\hline
\end{tabular}

Fonte: www.phizer.com.br

\subsubsection{Prejuízos diretos}

A região sul do Rio Grande do Sul é a maior área endêmica de fasciolose. De um total de 60 mil bovinos abatidos no ano de 2003 naquela região, $28,56 \%$ tiveram os fígados condenados por fasciolose para o consumo humano. Levando-se em consideração que um fígado bovino pesa cerca de 5 $\mathrm{Kg}$ e que o $\mathrm{Kg}$ custa $\mathrm{R} \$ 3,00$, a condenação de fígados resulta em uma perda de $R \$ 15,00 /$ fígado para o frigorífico. Nos frigoríficos do Mercosul (Extremo Sul, Bagé, Alegrete e Mato Leitão) onde foram abatidos em média $460 \mathrm{mil}$ bovinos no ano de $2003,43,5 \%$ dos fígados foram condenados por fasciolose e hidatidose, resultando num prejuízo de em torno de $\mathrm{R} \$ 3$ milhões (ANTUNES, 2005). 


\subsubsection{Prejuízos indiretos}

Geralmente a fasciolose não é letal aos bovinos, induzindo os pecuaristas a não considerá-la um problema. Porém, a doença ocasiona lesões no fígado e interfere no metabolismo, comprometendo o desempenho produtivo e reprodutivo do rebanho. Estas lesões hepáticas também servem como porta de entrada para infecções por Clostridium haemolyticum, causando a hemoglobinúria baciliar ( $\mathrm{HB})$, doença considerada letal para o rebanho. A alta incidência de $\mathrm{HB}$ em regiões baixas e alagadiças pode ser relacionada à ocorrência de fasciolose (ANTUNES, 2005).

\subsection{DIAGNÓSTICO}

A fasciolose deve ser considerada quando da investigação das causas de anemia, perda da condição corporal ou mortalidade de ovinos e bovinos pastejando áreas favoráveis à ocorrência de $F$. hepatica. No caso de animais mortos, a presença dos parasitos adultos ou imaturos pode ser facilmente detectada no fígado

$\mathrm{Na}$ fase aguda ou subaguda podem-se empregar testes laboratoriais que medem o nível plasmático de enzimas como a glutamato dehidrogenase e glutamato oxalacetato aminotransferase (início da infecção até fase no parênquima) e também a gama-glutamil transferase (lesão ductos biliares) que são liberadas em maior quantidade na corrente sanguínea conforme a fase de evolução dos parasitos. Já a fasciolose crônica pode ser diagnosticada pela presença de ovos nas fezes, usando-se para isto técnicas baseadas no princípio de sedimentação ou no de tamisação progressiva. Esta última, muito fácil de ser usada, consiste na utilização de quatro peneiras de diferentes aberturas que permitem a retenção progressiva da maior parte de outros elementos, deixando na última um sedimento com os ovos da fasciola (GIRÃO, 1985). Ao examinar-se este sedimento sob um estereomicroscópio, deve-se ter o cuidado de não confundir os ovos de F. hepatica (amarelados, cheios de grânulos finos e com núcleo descentralizado) com os de Paramphistomum (esbranquiçados, 
com poucos grânulos e com o núcleo descentralizado) (GIRÃO, 1985).

O diagnóstico clínico da fasciolose é difícil, podendo ser confundido com outras doenças, tornando-se necessário o diagnóstico laboratorial. 0 diagnóstico rotineiro para $F$. hepatica é o exame coproparasitológico de sedimentação, realizado mediante a observação dos ovos do parasito. No entanto, este método só é eficiente se aplicado após o período de pré-patência e sua sensibilidade é significativamente reduzida em situações de fraca infecção (até 30\% para animais que apresentam reduzido número de ovos nas fezes) (MATTOS et al., 2009).

Apesar de existir uma tendência nos últimos anos à aplicação de técnicas de imunodiagnóstico, como a detecção de antígenos através de imunoensaio enzimático, esta técnicas não são aplicáveis na prática diária do diagnóstico nos laboratórios clínicos, pois a relação custo-benefício não justifica seu emprego (WHO, 1992). As técnicas de diagnóstico coproparasitológico são as mais utilizadas nos programas de controle do parasitismo intestinal por seu baixo custo, simplicidade e sensibilidade.

\subsubsection{Imunodiagnóstico}

A utilização de técnicas de diagnóstico baseada na detecção de anticorpos contra antígenos do parasito representa uma importante contribuição para uma identificação rápida e em grande escala de animais infectados. O diagnóstico sorológico apresenta-se como uma ferramenta importante para estudos epidemiológicos, por ser capaz de detectar estágios iniciais das infecções. A detecção da infecção no estágio inicial é importante para a escolha do antihelmintico a ser administrado e para uma redução dos custos da quimioprofilaxia, pois existem diferenças quanto à atividade e custo econômico dos fasciolicidas disponível no mercado (SANCHEZ-ANDRADE et al., 2000).

Tipos variados de antígenos de $F$. hepatica têm sido utilizados em diferentes testes sorológicos. A técnica de diagnóstico imunoenzimático, ELISA (Enzyme Linked Immuno Sorbent Assay), utilizando antígenos de 
excreção/secreção (proteínas nativas) de $F$. hepatica (FhES), tem se mostrado sensível e específica para a detecção de IgG específica para o parasito em bovino, ovino e caprino com duas a quatro semanas de infecção experimental (TRUDGETT et al., 1988; SANTIAGO \& HILLYER, 1988; SANCHEZ-ANDRADE et al., 2000). Proteínas purificadas e recombinantes de $F$. hepatica também têm sido testadas para o diagnóstico sorológico. Estudos relatam o uso de proteínas purificadas do parasito como antígeno para a detecção sorológica de fasciolose em bovinos e ovinos (ABDEL-RAHMAN et al. 1998).

Contudo, um dos principais inconvenientes da utilização de ELISAindireto como método de diagnóstico da infecção por $F$. hepática é a persistência de elevados títulos de IgG por longos períodos, não permitindo a distinção entre infecção ativa e infecção precedente. Estudos demonstram que os níveis de IgG persistem em muitos animais, dando resultados positivos no ELISA por até 12 semanas pós-tratamento antihelminticos (CASTRO et al., 2000; SANCHEZ-ANDRADE et al., 2002).

\subsection{ANTIHELMINTICOS}

O período de 1960 a 1980 apresentou sucesso no desenvolvimento de drogas antihemínticas. As últimas décadas destinaram-se a pesquisa de novas drogas com diferentes estruturas, atividades e margens de segurança, produzidas pelo crescente Mercado das Indústrias farmacêuticas. Foi dado preferência a moléculas com sítios de atividade específicos para o parasito e o hospedeiro, bem como preocupação com aumento dos casos de resistência as drogas (BIANCHIN, 2000).

Ao se administrar um antiparasitário animal objetiva-se a eliminação do agente, ou o que é mais comum, manutenção de uma carga-parasitária a níveis toleráveis pelo hospedeiro, pois não existe vermífugo contra todos os tipos de parasitos e para todas as fases de seu desenvolvimento. Geralmente, a administração de antiparasitários é curativa em carnívoros e profilática em grandes animais. É desejável que o antiparasitário apresente eficiência capaz 
de destruir a maior percentagem possível, na maioria das fases do desenvolvimento (recomenda-se eficiência de $95 \%$, considerando-se ineficiente abaixo de $75 \%$ ); ser isento de efeitos colaterais (alguns antiparasitários não apresentam seletividade, atingindo assim as células do hospedeiro); baixa toxicidade ao hospedeiro e ao ambiente; não deixar resíduos do produto no animal; possibilidade de administração por diversas vias; maior índice terapêutico possível; baixo custo e facilidade na administração.

Entre as vias de administração consideram-se as mais utilizadas as vias intramuscular (IM) ou subcutânea (SC). A via Intrarumenal (IR) apresenta possibilidade de desenvolvimento de peritonite, embora os ruminantes apresentem elevada capacidade de "restrição" a estas infecções, reduzindo assim o seu risco. A via oral (VO) apresenta limite de emprego, tendo em vista a dificuldade de aplicação para bovinos, sendo indicada para animais de companhia. Já a via transcutânea utiliza formulações do tipo spot-on ou pouron, permitindo a absorção do vermífugo na pele através de veículo especial ou percutânea e Bolus (comprimido revestido destinado a liberação lenta do ativo) (VIANA, 2000).

Vale destacar que a via de administração do vermífugo não é o mais importante, o fundamental é o princípio ativo do produto. De nada adianta usar o melhor antihelmíntico do mercado, se este for aplicado em categorias de animais inadequadas, ou em épocas do ano erradas. Cerca de $80 \%$ das doses utilizadas no país são dadas erradamente e, portanto, sem retorno econômico (BIANCHIN, 2000).

\section{CONSIDERAÇÕES FINAIS}

Considerada uma zoonose com ampla distribuição geográfica, presente em nas regiões Centro-Oeste, Nordeste, Sul e Sudeste do Brasil, além de diversos países da América Latina, a fasciolose, é capaz de limitar a criação de diversas espécies de animais domésticos de interesse zootécnico, além de acometer o homem como hospedeiro ocasional. 
O diagnóstico clínico da fasciolose é difícil, podendo ser confundido com outras patologias, sendo necessário o diagnóstico laboratorial. Dentre as técnicas de diagnóstico, o exame coproparasitológico revela-se como o mais utilizado nos programas de controle do parasitismo intestinal por seu baixo custo, simplicidade e sensibilidade. Todavia, técnicas imunoenzimáticas representam uma relevante alternativa de contribuição neste controle, por apresentar rápida identificação, podendo ser aplicado em uma vasta escala de animais infectados.

O tratamento para fasciolose é essencial, a fim de minimizar as perdas associadas com condenações de fígados, mortalidade, redução em produção de carne, lã e leite, às infecções bacterianas secundárias e à interferência com a fertilidade. Assim, o tratamento deve ser realizado sob a forma de controle de vetores e tratamento farmacológico dos doentes, o que, deve ser realizado preferencialmente por antihelmínticos que apresentam fácil aplicação, evitando resíduos na carne e leite, e que sejam altamente eficazes contra formas adultas e imaturas de $F$. hepatica. Assim, o fundamental para a escolha de um tratamento eficiente refere-se à escolha do princípio ativo do produto, visto que o antihelmíntico deve ser escolhido conforme categorias de animais e períodos de aplicação recomendados pelos protocolos dos órgãos competentes.

\section{REFERÊNCIAS BIBLIOGRÁFICAS}

ABDEL-RAHMAN S.M., O'REILY K.L., MALONE, J.B. Evaluation of a diagnostic monoclonal antibody-based capture enzyme-linked immunosorbent assay for detection of a 26- to 28-kDa Fasciola hepatica coproantigens in cattle. American Journal of Veterinary Research, 59:533-537, 1998.

ANTUNES, G. M. Inimigo Oculto, Revista Cultivar Bovinos, V.15, p.1-4, 2005.

BARROS, J.S.L; PILE, E.A.M; VASCONCELLOS, M.C; et al. Experimental infection of Physa cubensis Pfeiffer, 1839 and Lymnaea columella with Fasciola hepatica miracidiae Linnaeus, 1758 Brazilian Journal of Veterinary Research and Animal Science, V. 39, n.3, p.121123, 2002.

BIANCHIN, I. O controle da verminose de bovinos nelore no cerrado. Disponível em: http://www.neloresantamaria.com.br/artigo_9.htm, acessado em 23 de outubro de 2011. 
BOTELHO, G.B.; SOUZA, A..P; BELLATO, V. et al. Prevalence of Fasciola hepatica in five counties of the extreme south of Santa Catarina. Brazilian Journal of Veterinary Research and Animal Science, V. 39, n. 3, p.121-123, 2002.

CASTRO, E.; FREYRE, A.; HERNANDEZ, Z. Serological responses of cattle after treatment and during natural reinfection with Fasciola hepatica, as measured with a dot-ELISA system. Veterinary Parasitology. 90: 201- 208, 2000.

CORAL, R.P.; MASTALIR, E.T.; MASTALIR, F.P. Retirada de Fasciola hepatica da via biliar principal por coledocospia. Revista do Colégio Brasileiro de Cirurgiões. V. 34, n. 1, p. 6971, 2007.

ECHEVARRIA, F.A.M. Fasciolose. Revista Brasileira Parasitologia Veterinária, v. 13, n. 1, p. $100-102,2004$.

GIRÃO, E.S.; UENO, H. Técnica de Quatro tamises para o diagnóstico coprológico quantitativo da fasciolose dos ruminantes. Pesquisa Agropecuária Brasileira, v.20, n.8, p. 905-912, 1985.

MATTOS, M.J.T.; CUNHA, F.O.V.; MARQUES, S.M.T. Comparison of two parasitological technics in identificacion of eggs with Fasciola hepatica. Revista da FZVA. 16(1):105-112, 2009.

MÜLLER, G.; LARA, S.I.M.; SILVEIRA, J.P. et al. Acompanhamento laboratorial do ciclo biológico de Lymnaea viatrix, hospedeiro intermediário de Fasciola hepatica. Revista Brasileira de Agrociências, V. 4, n. 3, p. 172-176, 1998.

SANCHEZ-ANDRADE， R.; PAZ-SILVA, A.; SUÁREZ, J.; PANADERO R.; DÍEZ-BAÑOS, P., MORRONDO P. Use of a sandwich-enzyme-linked immunosorbent assay (SEA) for the diagnosis of natural Fasciola hepatica infection in cattle from Galicia (NW Spain). Veterinary Parasitology, 93: 39-46, 2000.

SANTIAGO, N; HILLYER G.V. Antibody profiles by EITB and ELISA of cattle and sheep infected with Fasciola hepatica. Journal of Parasitology, 74: 810-818, 1988.

SERRA-FREIRE, N.M.; BORDIN, E.L.; LESSA, C.S.S. et al. Reinvestigação sobre a distribuição da Fasciola hepatica no Brasil. A Hora Veterinária, V. 1, p.19-21, 1995.

TRUDGETT, A.; ANDERSON, A.; HANNA, E.M. Use of immunosorbent-purified antigens of Fasciola hepatica in enzyme immunoassays. Research Veterinary Science, 44:262-263, 1988.

VIANA, F.A.B.; MUNDIM, A.C.; LEITE, C.A.L et al. Fundamentos da Medicina Veterinária, ed. UFMG, V. 1, p. 324, 2000. 